\title{
Colorimetric Detection of Glucose in Biological Fluids Using Toner-Based Microzone Plates
}

\author{
Paula B. M. Silva, ${ }^{a}$ Karoliny A. Oliveira ${ }^{a}$ and Wendell K. T. Coltro ${ }^{*, a, b}$ \\ ${ }^{a}$ Instituto de Química, Universidade Federal de Goiás, 74001-970 Goiânia-GO, Brazil \\ ${ }^{b}$ Instituto Nacional de Ciência e Tecnologia de Bioanalítica, INCTBio, 13083-861 Campinas-SP, Brazil
}

\begin{abstract}
This report describes the use of toner-based microzone plates for quantitative determination of glucose in artificial urine and human serum samples using colorimetric detection. The proposed approach has exhibited a linear response for glucose concentration levels from 0 to $10 \mathrm{mmol} \mathrm{L}^{-1}$ with determination coefficient $\left(\mathrm{R}^{2}\right)$ of 0.996 . The achieved values for sensitivity and limit of detection were $5.1 \mathrm{AU}\left(\mathrm{mmol} \mathrm{L}^{-1}\right)^{-1}$ and $0.6 \mathrm{mmol} \mathrm{L}^{-1}$, respectively. The glucose analysis in artificial serum samples revealed error lower than $5 \%$ in comparison with certified values provided by the supplier. Lastly, the proposed approach has also provided suitable accuracy (92-105\%) for glucose measurements in artificial urine samples.
\end{abstract}

Keywords: bioanalytic, clinical assay, disposable device, point-of-care testing, portable instrumentation

\section{Introduction}

In the last years, the miniaturization of analytical systems has received considerable attention due to their attractive advantages including low reagent and sample consumption, portability, minimal waste generation, short time analysis, and high-throughput capability. ${ }^{1-7}$ Standard photolithography is one of the main microfabrication technologies allowing the fabrication of microfluidic channels on different platforms including glass, silicon and quartz. Although this technology provides excellent resolution, it is laborious, expensive and time consuming. ${ }^{8,9}$ Furthermore, cleanroom facilities and sophisticated instrumentation are required thereby limiting the access to few research groups. For this reason, simpler, cheaper and faster technologies have been developed to promote the rapid spread of miniaturized analytical systems worldwide. ${ }^{10-12}$ Among the alternative fabrication methodologies, tonerbased techniques offer simplicity and low instrumental requirements, thus making possible their implementation in any laboratory or research center. ${ }^{13,14}$

Toner was firstly explored for microfabrication in 2001, when Tan et al. ${ }^{15}$ suggested the use of a photocopying machine to create a high-relief master for prototyping of microfluidic devices in poly(dimetilsyloxane) (PDMS)

*e-mail: wendell@ufg.br substrate. In 2003, do Lago et al. ${ }^{16}$ proposed the direct fabrication of microfluidic devices using a laser printer for the deposition of toner layers on polyester films followed by a thermal lamination for sealing of channels at low temperature. Since this pioneering report, laser printing technology (LPT) has been used to produce microfluidic toner-based analytical devices ( $\mu$ TADs) at very low cost. As previously reviewed, ${ }^{13}$ examples of toner-based devices for electrophoretic separations, deoxyribonucleic acid (DNA) extraction and analysis, polymerase chain reaction (PCR) amplification, passive micromixers, protein concentrator and electrospray tips have been successfully reported. Recent publications have also demonstrated the use of LPT to produce tunable hydrophobic valves ${ }^{17}$ as well as polyester-toner devices for microdroplets generation ${ }^{18}$ and reciprocating mixers. ${ }^{19}$ Additional examples regarded to the indirect use of toner for the fabrication of electroanalytical devices, ${ }^{20-25}$ microchip free-flow electrophoresis,${ }^{26}$ polymer microfluidic devices ${ }^{27-29}$ and integrated microfluidic cell devices have been also reported. ${ }^{30}$

Due to the advantages associated with the fabrication simplicity and low cost per device, some authors have extended the use of LPT to produce toner-based devices for clinical assays involving the use of portable equipment like cell phone camera, scanner, digital camera and handheld optical microscope for colorimetric measurements. The association of toner-based devices and colorimetric 
detection is quite attractive for point-of-care (POC) testing due to operational simplicity and low instrumental requirements. Furthermore, the mentioned electronic devices for image capture are globally affordable and their use do not require extensive training. This platform has been successfully used for capillary-driven flow based clinical assays ${ }^{31}$ and dengue diagnostics through enzyme-linked immunosorbent assay (ELISA) on printed zones. ${ }^{32}$ When compared to capillary-driven toner-based microfluidic devices, the laser printing of microzone array on transparency films is based on a single printing step, ${ }^{32}$ while the fabrication of multilayer toner-based microfluidic devices require the laser cut of an intermediary transparency film, an alignment step and, finally, a thermal lamination to promote the channel sealing. ${ }^{31}$

In this current report, we describe the use of tonerbased microzone plates for glucose analysis in biological fluids using colorimetric measurements. Glucose has been selected as a target analyte because of its clinical importance for diagnosis and monitoring of diabetes. ${ }^{33}$ Colorimetric measurements were performed on printed toner zones filled with cellulose paste. Glucose concentration levels were quantitatively determined in artificial serum and urine samples.

\section{Experimental}

\section{Materials and chemicals}

Cellulose powder, glucose oxidase $\left(181 \mathrm{U} \mathrm{mg}^{-1}\right)$, $D$-glucose, horseradish peroxidase (HRP) $\left(73 \mathrm{U} \mathrm{mg}^{-1}\right)$, potassium iodide, sodium monohydrogen phosphate, and sodium dihydrogen phosphate were purchased from Sigma-Aldrich Co. (Saint Louis, MO, USA). Artificial serum samples level I (lot No. SCNO 13041) and level II (lot No. SCPA 12081) were acquired from Doles Reagents (Goiania, GO, Brazil). Transparency films (Filipaper Pro $100-\mu$ model) and toner cartridge CB540A were obtained from Filiperson (Rio de Janeiro, RJ, Brazil) and HewlettPackard (Palo Alto, CA, USA), respectively. All chemicals were used without any purification.

\section{Fabrication of toner-based microzone plates}

Toner-based microzone plates were fabricated according to the procedure reported by our group. ${ }^{32}$ Microplates were drawn in Corel Draw software version 13.0 and then printed on a polyester film surface using a laser printer with 1200-dpi resolution (model LaserJet 1102w, Hewlett-Packard). The toner provided a hydrophobic barrier restricting the area for bioassays. The layout of the microplate consisted in 33 wells arranged into 11 columns with 3 wells each, as depicted in Figure 1.

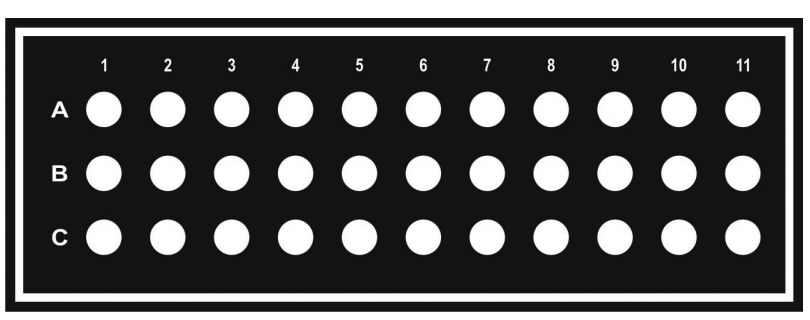

Figure 1. Layout of the microplate containing 33 wells arranged into 11 columns with 3 wells each.

\section{Colorimetric detection}

Colorimetric detection was performed using the scanner mode of a Deskjet multifunction printer (HewlettPackard, model F4280), with 600-dpi resolution. The images were converted to 8-bit grayscale and analyzed in Corel Photo-Paint software. The arithmetic mean intensity of each pixel was used to measure the color intensity.

\section{Glucose assay}

Prior to the colorimetric assays, $15 \mu \mathrm{L}$-aliquots of a cellulose paste made of cellulose powder and water $(1: 4 \mathrm{~m} / \mathrm{v})$ were added to the zones and allowed to dry at room temperature. Afterwards, $10 \mu \mathrm{L}$ of $0.6 \mathrm{~mol} \mathrm{~L}^{-1}$ potassium iodide solution and $10 \mu \mathrm{L}$ of a solution containing HRP and glucose oxidase enzymes (1:5) prepared in $100 \mathrm{mmol} \mathrm{L}^{-1}$ phosphate buffer $(\mathrm{pH}$ 6) were manually pipetted inside each microzone. The microplate was kept at room temperature during 30 minutes to dry. Finally, $10 \mu \mathrm{L}$ of standard or artificial sample solution were added into the microzones.

\section{Biological samples}

Artificial samples of human urine and serum were used to demonstrate the analytical and clinical feasibility the proposed approach. Artificial urine solution was prepared according to the procedure described by Martinez et al. ${ }^{34}$ The solution was prepared with 1.1, 2.0, 25, 70, 2.5, 90, $10,2.0,7.0,7.0$ and $25 \mathrm{mmol} \mathrm{L}^{-1}$ of lactic acid, citric acid, sodium bicarbonate, urea, calcium chloride, sodium chloride, sodium sulfate, magnesium sulfate, potassium monohydrogen phosphate, potassium dihydrogen phosphate and ammonium chloride, respectively. The final volume was adjusted to $200 \mathrm{~mL}$ with ultrapure water and the $\mathrm{pH}$ was adjusted to 6.0 using hydrochloric acid $\left(1.0 \mathrm{~mol} \mathrm{~L}^{-1}\right)$. Artificial serum samples levels I and II were obtained from Doles Reagents (Goiânia, GO, Brazil). 
Standard, artificial and diluted solutions were prepared using ultrapure water processed through a water purification system (Direct- $Q^{\circledR} 3$, Millipore, Darmstadt, Germany) with resistivity equal to $18.2 \mathrm{M} \Omega \mathrm{cm}$. Recovery experiments were carried out to study the accuracy of the proposed methodology for glucose analysis. For this purpose, artificial urine samples were spiked with glucose standard solutions at three concentration levels $(2,4$ and $\left.6 \mathrm{mmol} \mathrm{L}^{-1}\right)$.

\section{Results and Discussion}

The toner layer printed on polyester surface provides an effective hydrophobic barrier for chemical or biochemical assays performed on zones or wells defined in white color during the laser printing step. In this area, the printer does not deposit toner allowing the production of zones according to desirable dimensions. The limitation of this technology makes reference to the toner layer thickness, which depends on the laser printer resolution. According to a previous report, the printed zones are defined with a depth of ca. $5 \mu \mathrm{m}$ (equivalent to the toner layer thickness). ${ }^{32}$ When compared to wax printing technology ${ }^{35}$ recognized as one of the simplest methods to produce paper-based analytical devices, the laser printing allows the fabrication of microzone plates in a single printing step using simpler instrumentation. In this current report, zones were filled with a cellulose paste to ensure the retention of the added reagents and to provide a better color distribution on the whole zone. Moreover, this strategy improved the repeatability of colorimetric measurements through digital images captured with a scanner and prevented the interference of external light commonly observed in the drop formed inside microzones. ${ }^{32}$

Glucose colorimetric assay was then carried out using toner-based microzones filled with cellulose paste. The reaction is based on glucose conversion to gluconic acid and hydrogen peroxide by glucose oxidase (GOx) enzyme in the presence of HRP, which catalyzes the reduction of hydrogen peroxide and the oxidation of iodide to molecular iodine. These sequential reactions promote a color change from colorless to brown. ${ }^{34,36}$ Figure 2 displays an optical micrograph showing developed color for glucose concentration levels from 0 (column 1) to $10 \mathrm{mmol} \mathrm{L}^{-1}$ (column 11). As it can be seen, the higher the concentration, the stronger the color intensity.

In order to obtain quantitative information from scanned images, the pixel intensity values were determined using a graphic software which allowed the glucose analysis in biological fluids. For this purpose, images were scanned after a reaction time of $15 \mathrm{~min}$,

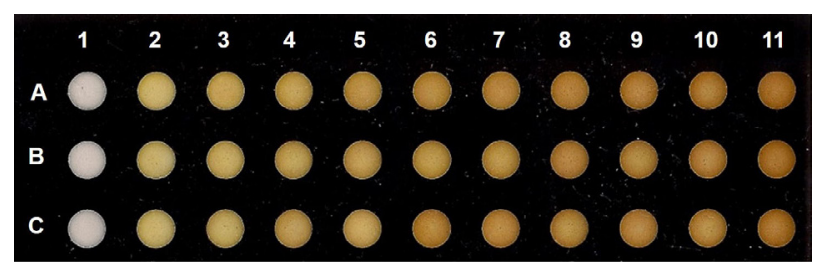

Figure 2. Optical micrograph showing colorimetric assays for glucose at concentration levels ranging from 0 (column 1) to $10 \mathrm{mmol} \mathrm{L}^{-1}$ (column 11) with $1 \mathrm{mmol} \mathrm{L}^{-1}$ increments.

as previously optimized. ${ }^{37}$ The resulting color intensity was taken into consideration to establish a relationship with the analytical concentration. Figure 3 presents a good correlation between the color intensities and glucose concentrations. The analytical curve varied from 0 to $10 \mathrm{mmol} \mathrm{L}^{-1}$ exhibited a great relationship with a coefficient determination $\left(\mathrm{R}^{2}\right)$ equal to 0.996 . The limit of detection (LOD) and analytical sensitivity achieved were $0.6 \mathrm{mmol} \mathrm{L}^{-1}$ and $5.1 \mathrm{AU}\left(\mathrm{mmol} \mathrm{L}^{-1}\right)^{-1}$, respectively. The LOD value was calculated based on the color intensity related to three times the standard deviation of the control zone and the angular coefficient of the analytical curve.

The LOD achieved on printed zones is better than the value previously reported using capillary-driven tonerbased microfluidic devices. ${ }^{31}$ The reason is associated with the poor color homogeneity inside detection zones on toner-based microfluidic devices. The poor uniformity is caused due to the weak interaction between enzymes and/or colorimetric indicators with the substrate surface allowing their loading to zone borders, thus resulting in the formation of a color gradient. In addition, the found LOD is similar to the value obtained using microfluidic cloth-based analytical devices ( $\mu$ CADs) $)^{38}$ and slightly higher than the LOD's achieved in representative articles on microfluidic paper-based analytical devices ${ }^{34,36,39-42}$ and $\mu \mathrm{CADs}$ coupled with electrochemiluminescence and colorimetric detectors. ${ }^{43,44}$

The precision of the colorimetric measurements was investigated aiming the intra and inter-microplate comparisons. For this purpose, a standard glucose solution was added inside microzones and analyzed under similar experimental conditions during five consecutive weeks. The relative standard deviation (RSD) values recorded for the intraplate measurements $(\mathrm{n}=3)$ ranged from 0.4 to $2.0 \%$. On the other hand, the RSD found for the colorimetric response in an interplate comparison $(\mathrm{n}=5)$ was $6.1 \%$. As referenced by Dungchai et al., ${ }^{36}$ the normal glucose levels in serum and urine are 2.5-5.3 and 0.1-0.8 $\mathrm{mmol} \mathrm{L}^{-1}$, respectively. In addition, concentration levels above $7.0 \mathrm{mmol} \mathrm{L}^{-1}$ in serum and $1.4 \mathrm{mmol} \mathrm{L}^{-1}$ in urine samples may be indicative of diabetes mellitus or other disorder. ${ }^{34}$ Based on the analytical performance of the proposed hybrid 
toner-cellulose zones, the LOD, the linear concentration range and the inter and intraplates comparisons achieved make the use of this disposable platform possible for clinical studies using biological samples.

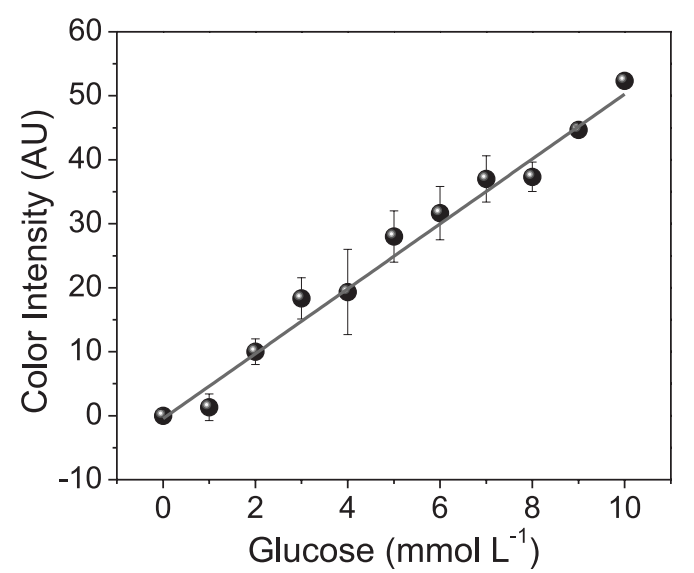

Figure 3. Calibration curve for glucose assay. The symbol and the error bars mean the average and standard deviation values $(n=3)$, respectively. The linear regression equation obtained was $\mathrm{y}=-0.46+5.10 \mathrm{x}$.

\section{Biological samples}

The clinical feasibility of the toner-based platform was demonstrated using artificial serum and urine samples. Firstly, artificial serum samples (levels I and II) with certified concentration levels were analyzed according to the procedure described earlier. While serum sample level I was prepared without dilution, the serum sample level II was diluted in water $(1: 2, \mathrm{v} / \mathrm{v})$. Based on the analytical curve shown in Figure 3, the glucose concentrations found in both serum samples were calculated and the values are presented in Table 1. As it can be seen in the comparative data, the values achieved are in agreement with the certified values and supplied by the manufacturer with error lower than 5\%.

Likewise serum samples, artificial urine samples were also tested for glucose analysis on printed microzones. For this purpose, urine samples were spiked with three glucose concentration levels $\left(2.0,4.0\right.$ and $\left.6.0 \mathrm{mmol} \mathrm{L}^{-1}\right)$. The glucose concentrations achieved in all three urine samples were $1.9 \pm 0.3,4.2 \pm 0.2$ and $5.5 \pm 0.5 \mathrm{mmol} \mathrm{L}^{-1}$, thus revealing good accuracy $(92-105 \%)$.

Table 1. Comparison between the certified values and values found in artificial serum samples using toner-based microplates

\begin{tabular}{lccc}
\hline Sample & $\begin{array}{c}\text { Certified value / } \\
\left(\mathrm{mmol} \mathrm{L}^{-1}\right)\end{array}$ & $\begin{array}{c}\text { Found value / } \\
\left(\mathrm{mmol} \mathrm{L}^{-1}\right)\end{array}$ & Error / \% \\
\hline Level I & $4.3-5.7$ & $5.1 \pm 0.4$ & 2.0 \\
Level II & $12.4-16.2$ & $13.6 \pm 0.4$ & -4.9 \\
\hline
\end{tabular}

\section{Conclusions}

In summary, printed microzones have been successfully used for colorimetric analysis of glucose in artificial biological samples. Toner-based microzones were printed on polyester film and filled with a cellulose paste. This strategy ensured acceptable analytical performance for clinical applications. The achieved LOD $\left(0.6 \mathrm{mmol} \mathrm{L}^{-1}\right)$ as well as the linear concentration range $\left(0-10 \mathrm{mmol} \mathrm{L}^{-1}\right)$ and the acceptable accuracy (92-105\%) make this technology quite attractive for diagnosis of diabetes or other disorder associated with glucose concentration levels. The advantages related to the use of polyester-toner devices (low cost, ease of fabrication and low instrumental requirements) in association with colorimetric measurements through portable electronic devices can be useful for POC testing. Future advances may enable the use of a color scale to allow the direct and visual analysis of glucose concentrations. This can result in an important tool for clinical screening.

\section{Acknowledgments}

This project has been supported by Conselho Nacional de Desenvolvimento Científico e Tecnológico (CNPq) grant No. 448089/2014-9 and Fundação de Amparo a Pesquisa do Estado de Goiás (FAPEG). The authors gratefully acknowledge the scholarships granted from Coordenação de Aperfeiçoamento de Pessoal de Nível Superior (CAPES) to $\mathrm{KAO}$ and from CNPq to PBMS as well as the researcher fellowship granted from CNPq to WKTC (grant No. 311744/2013-3).

\section{References}

1. Castro, E. R.; Manz, A.; J. Chromatogr. A 2015, 1382, 66.

2. Arora, A.; Simone, G.; Salieb-Beugelaar, G. B.; Kim, J. T.; Manz, A.; Anal. Chem. 2010, 82, 4830.

3. Kovarik, M. L.; Ornoff, D. M.; Melvin, A. T.; Dobes, N. C.; Wang, Y. L.; Dickinson, A. J.; Gach, P. C.; Shah, P. K.; Allbritton, N. L.; Anal. Chem. 2013, 85, 451.

4. Culbertson, C. T.; Mickleburgh, T. G.; Stewart-James, S. A.; Sellens, K. A.; Pressnall, M.; Anal. Chem. 2014, 86, 95.

5. Patabadige, D. E.; Jia, S.; Sibbitts, J.; Sadeghi, J.; Sellens, K.; Culbertson, C. T.; Anal. Chem. 2016, 88, 320.

6. Haeberle, S.; Zengerle, R.; Lab Chip 2007, 7, 1094.

7. Medina-Sanchez, M.; Miserere, S.; Merkoci, A.; Lab Chip 2012, 12, 1932.

8. Chen, Y.; Pepin, A.; Electrophoresis 2001, 22, 187.

9. Lima, R. S.; Leao, P. A.; Piazzetta, M. H.; Monteiro, A. M.; Shiroma, L. Y.; Gobbi, A. L.; Carrilho, E.; Sci. Rep. 2015, 5, 13276. 
10. Becker, H.; Gartner, C.; Anal. Bioanal. Chem. 2008, 390, 89.

11. Fonseca, A.; Raimundo Jr., I. M.; Rohwedder, J. J.; Ferreira, L. O.; Anal. Chim. Acta 2007, 603, 159.

12. Fonseca, A.; Silva, J. D. B.; J. Braz. Chem. Soc. 2013, 24, 5.

13. Coltro, W. K. T.; de Jesus, D. P.; da Silva, J. A. F.; do Lago, C. L.; Carrilho, E.; Electrophoresis 2010, 31, 2487.

14. Thompson, B. L.; Ouyang, Y. W.; Duarte, G. R. M.; Carrilho, E.; Krauss, S. T.; Landers, J. P.; Nat. Protoc. 2015, 10, 875.

15. Tan, A. M.; Rodgers, K.; Murrihy, J. P.; O’Mathuna, C.; Glennon, J. D.; Lab Chip 2001, $1,7$.

16. do Lago, C. L.; da Silva, H. D. T.; Neves, C. A.; Brito-Neto, J. G. A.; da Silva, J. A. F.; Anal. Chem. 2003, 75, 3853.

17. Ouyang, Y.; Wang, S.; Li, J.; Riehl, P. S.; Begley, M.; Landers, J. P.; Lab Chip 2013, 13, 1762.

18. Piccin, E.; Ferraro, D.; Sartori, P.; Chiarello, E.; Pierno, M.; Mistura, G.; Sens. Actuator, B 2014, 196, 525.

19. Ouyang, Y. W.; Li, J. Y.; Phaneuf, C.; Riehl, P. S.; Forest, C.; Begley, M.; Haverstick, D. M.; Landers, J. P.; Lab Chip 2016, 16,377 .

20. da Silva, R. A. B.; de Almeida, E. G. N.; Rabelo, A. C.; da Silva, A. T. C.; Ferreira, L. F.; Richter, E. M.; J. Braz. Chem. Soc. 2009, 20, 1235.

21. de Souza, A. P. R.; Felix, F. S.; Dantas, L. M. F.; Angnes, L.; Bertotti, M.; Sens. Actuators, B 2014, 203, 406.

22. de Souza, A. P. R.; Felix, F. S.; Castro, P. S.; Angnes, L.; Bertotti, M.; Anal. Methods 2016, 8, 1078.

23. Richter, E. M.; Munoz, R. A. A.; Bertotti, M.; Angnes, L.; Electrochem. Commun. 2007, 9, 1091.

24. Lowinsohn, D.; Richter, E. M.; Angnes, L.; Bertotti, M.; Electroanalysis 2006, 18, 89.

25. Daniel, D.; Gutz, I. G. R.; Electrochem. Commun. 2003, 5, 782.

26. de Jesus, D. P.; Blanes, L.; do Lago, C. L.; Electrophoresis 2006, 27, 4935.

27. Vullev, V. I.; Wan, J.; Heinrich, V.; Landsman, P.; Bower, P. E.; Xia, B.; Millare, B.; Jones, G.; J. Am. Chem. Soc. 2006, 128, 16062.

28. Thomas, M. S.; Millare, B.; Clift, J. M.; Bao, D.; Hong, C.; Vullev, V. I.; Ann. Biomed. Eng. 2010, 38, 21.
29. Easley, C. J.; Benninger, R. K.; Shaver, J. H.; Steven Head, W.; Piston, D. W.; Lab Chip 2009, 9, 1119.

30. Daniel, D.; Gutz, I. G. R.; Electrochem. Commun. 2007, 9, 522.

31. de Souza, F. R.; Alves, G. L.; Coltro, W. K. T.; Anal. Chem. 2012, 84, 9002.

32. Oliveira, K. A.; de Oliveira, C. R.; da Silveira, L. A.; Coltro, W. K. T.; Analyst 2013, 138, 1114.

33. Kaefer, M.; Piva, S. J.; de Carvalho, J. A. M.; da Silva, D. B.; Becker, A. M.; Coelho, A. C.; Duarte, M. M. M. F.; Moresco, R. N.; Clin. Biochem. 2010, 43, 450.

34. Martinez, A. W.; Phillips, S. T.; Carrilho, E.; Thomas, S. W.; Sindi, H.; Whitesides, G. M.; Anal. Chem. 2008, 80, 3699.

35. Carrilho, E.; Martinez, A. W.; Whitesides, G. M.; Anal. Chem. 2009, 81, 7091.

36. Dungchai, W.; Chailapakul, O.; Henry, C. S.; Anal. Chim. Acta 2010, 674, 227.

37. Oliveira, K. A.; Silva, P. B. M. E.; de Souza, F. R.; Martins, F. T.; Coltro, W. K. T.; Anal. Methods 2014, 6, 4995.

38. Wu, P. J.; Zhang, C. S.; Lab Chip 2015, 15, 1598.

39. Chen, X.; Chen, J.; Wang, F. B.; Xiang, X.; Luo, M.; Ji, X. H.; He, Z. K.; Biosens. Bioelectron. 2012, 35, 363.

40. Lankelma, J.; Nie, Z. H.; Carrilho, E.; Whitesides, G. M.; Anal. Chem. 2012, 84, 4147.

41. Chun, H. J.; Park, Y. M.; Han, Y. D.; Jang, Y. H.; Yoon, H. C.; BioChip J. 2014, 8, 218.

42. Zhu, W. J.; Feng, D. Q.; Chen, M.; Chen, Z. D.; Zhu, R.; Fang, H. L.; Wang, W.; Sens. Actuators, B 2014, 190, 414.

43. Guan, W. R.; Liu, M.; Zhang, C. S.; Biosens. Bioelectron. 2016, $75,247$.

44. Liu, M.; Zhang, C. S.; Liu, F. F.; Anal. Chim. Acta 2015, 891, 234.

Submitted: March 2, 2016

Published online: May 31, 2016

FAPESP has sponsored the publication of this article. 